\title{
Temperature influence and reset voltage study of bipolar resistive switching behaviour in $\mathrm{ZrO}_{2}$ thin films
}

\author{
YING LI ${ }^{1, *}$ GAOYANG ZHAO ${ }^{2}$, JIAN SU $^{2}$, ERFENG SHEN ${ }^{2}$ and YANG REN ${ }^{2}$ \\ ${ }^{1}$ Advanced Material Analysis Center, Xi' an University of Technology, Box 759\#, No. 5, Jinhua South Road, \\ Xi'an, Shaanxi 710048, China \\ ${ }^{2}$ Material Science and Engineering School, Xi' an University of Technology, Xi'an, Shaanxi 710048, China
}

MS received 4 February 2013; revised 1 April 2013

\begin{abstract}
We have fabricated $\mathrm{ZrO}_{2}$ thin films by sol-gel deposition and annealed them at 300,500 and $700{ }^{\circ} \mathrm{C}$. Reproducible $\mathrm{I}-\mathrm{V}$ curves can be obtained for the device $\mathrm{Cu} / \mathrm{ZrO}_{2} / \mathrm{ATO}$ which is measured at room temperature $(300 \mathrm{~K})$. During the RESET operation, $R_{\mathrm{L}}$ and $R_{\mathrm{H}}$ values can be controlled by the RESET voltage. Moreover, the $\mathrm{Cu} / \mathrm{ZrO}_{2} / \mathrm{ATO}$ device which the $\mathrm{ZrO}_{2}$ thin film annealed at $300{ }^{\circ} \mathrm{C}$ can be measured as resistive switching sweeps at 200,100 and $50 \mathrm{~K}$. It was found that the ratio of $R_{\text {off }} / R_{\text {on }}$ reduced when the measured temperature decreased. When the $I-V$ measurement temperature decreases, $R_{\text {on }}$ decreases obviously which is typical for electronic transportation in a $\mathrm{Cu}$ metal. It is indicated that the $\mathrm{Cu}$ metallic conduction filament has been formed in the $\mathrm{ZrO}_{2}$ films. Besides, the microstructure by high resolution transmission electrical microscopy (HRTEM) was also investigated.
\end{abstract}

Keywords. Resistive switching; TEM; $\mathrm{ZrO}_{2}$; low temperature.

\section{Introduction}

Resistive switching behaviours of thin films which are used in high density resistance random access memories (RRAM) have shown great promise for the next generation nonvolatile memory (NVM) (Ting et al 2000; Li et al 2011). Types of NVMs are several, such as ferroelectric random access memory (FRAM), RRAM and magnetic random access memory (MRAM). The intensive research and development of RRAM were triggered due to the low power consumption, high density integration and high speed operation. To achieve this controllability and repeatability of resistance, the controllability of switching voltage for both SET and RESET process is a key factor (Gao et al 2008). In addition, reducing switching voltage is also a desire for low power consumption for next generation nonvolatile memory. As for the resistive switching mechanism, there are several kinds of switching phenomena like redox effects in the resistance changes, filament formation and the percolation of the defects in the oxide (Choi et al 2005; Waser 2009). Researchers have used several techniques to investigate the mechanism such as conductive atomic force microscopy (C-AFM), high resolution transmission electrical microscopy (HRTEM) and scanning electrical microscopy (SEM) (Gopalan et al 2007; Guo et al 2007).

\footnotetext{
*Author for correspondence (liying@xaut.edu.cn)
}

In the recent study, we have investigated the influence of the temperature on the resistive switching behaviours of the sol-gel deposited $\mathrm{ZrO}_{2}$ thin film in the metaloxide-semiconductor structure. The $\mathrm{ZrO}_{2}$ thin films were annealed at different temperatures: 300,500 and $700{ }^{\circ} \mathrm{C}$. The bipolar resistive switching behaviour can be observed successfully in this structure. Successful $I-V$ sweeps were also observed at room temperature and low temperatures of 200, 100 and $50 \mathrm{~K}$ and HRTEM observation was used to study the interface between the layers.

\section{Experimental}

The whole process of fabrication is shown in the following. The substrate is self-made transparent and conductive $\mathrm{SnO}_{2}: \mathrm{F}$ (ATO) thin film on Si substrate (Zhi et al 2008). The ATO substrates were cleaned by proponal and acetone step by step. We used zirconium (IV) butoxide and ethanol as starting materials while benzoyl acetone $(\mathrm{BzAcH})$ as chemical modifier. The components zirconium (IV) butoxide, ethanol and $\mathrm{BzAcH}$ were mixed in terms of molar ratio $1: 20: 0 \cdot 8 . \mathrm{ZrO}_{2}$ solution could be obtained after stirring for $8 \mathrm{~h}$ in the glove box. Then, a dip-coating process was used to make a $\mathrm{ZrO}_{2}$ gel film on the ATO substrate. After annealing the gel films for 15 min, organic compounds were evaporated and $\mathrm{ZrO}_{2}$ thin films were obtained. The $\mathrm{ZrO}_{2}$ thin films being produced were annealed in air at different temperatures of 300, 500 and $700{ }^{\circ} \mathrm{C}$. Then, $\mathrm{ZrO}_{2}$ thin film was covered 
by a mask and copper (99.99\%) was evaporated by high vacuum thermal evaporation at $2 \times 10^{-4} \mathrm{~Pa}$ for $2.5 \mathrm{~min}$ at a speed of $20 \mathrm{~nm} / \mathrm{min}$. Finally, the metal-oxidesemiconductor structure $\mathrm{Cu} / \mathrm{ZrO}_{2} / \mathrm{ATO}$ was achieved.

Electrical measurements were performed by Keithley 2400 analyser at room temperature $(300 \mathrm{~K})$. I-V sweeps at low temperatures of 200, 100 and $50 \mathrm{~K}$ were also carried out by Versa Lab (Quantum design). The microstructural characterization was carried out by HRTEM (JEOL 3010, Japan). A cross-section of $\mathrm{Cu} / \mathrm{ZrO}_{2} / \mathrm{ATO}$ single unit device was successfully made by the low angle Argon milling machine (Gatan, USA). The milling angle was below $8^{\circ}$.

\section{Results and discussion}

Figure 1 presents the XRD patterns of $\mathrm{ZrO}_{2}$ thin films at various annealing temperatures. We observed the formation of amorphous $\mathrm{ZrO}_{2}$ thin films for annealing up to $700{ }^{\circ} \mathrm{C}$. Figure 1 (a) did not show any peaks of $\mathrm{ZrO}_{2}$. That means the $\mathrm{ZrO}_{2}$ thin film is amorphous. When the temperature increased to 500 and $700{ }^{\circ} \mathrm{C}, \mathrm{ZrO}_{2}$ thin film showed tetragonal phase occurring at $2 \theta=30 \cdot 1,34 \cdot 6$ and $50 \cdot 1^{\circ}$, which are attributed to $(101),(002),(112)$ reflections, respectively. It is in close agreement with the JCPDS card no. 81-1544. It shows that amorphous $\mathrm{ZrO}_{2}$ thin films changing to tetragonal phase up on annealing. As to ATO film, it also shows the tetragonal phase according to the card JCPDS no. 88-0287.

We took one unit of sample for TEM observations in which the $\mathrm{ZrO}_{2}$ thin film in the structure was annealed at 300, 500 and $700{ }^{\circ} \mathrm{C}$, respectively. Microstructural analysis has been done on the basis of TEM observations. Figure 2 shows the interface image of $\mathrm{Cu} / \mathrm{ZrO}_{2} / \mathrm{ATO}$ structure in which the $\mathrm{ZrO}_{2}$ thin film was annealed at $300{ }^{\circ} \mathrm{C}$. The

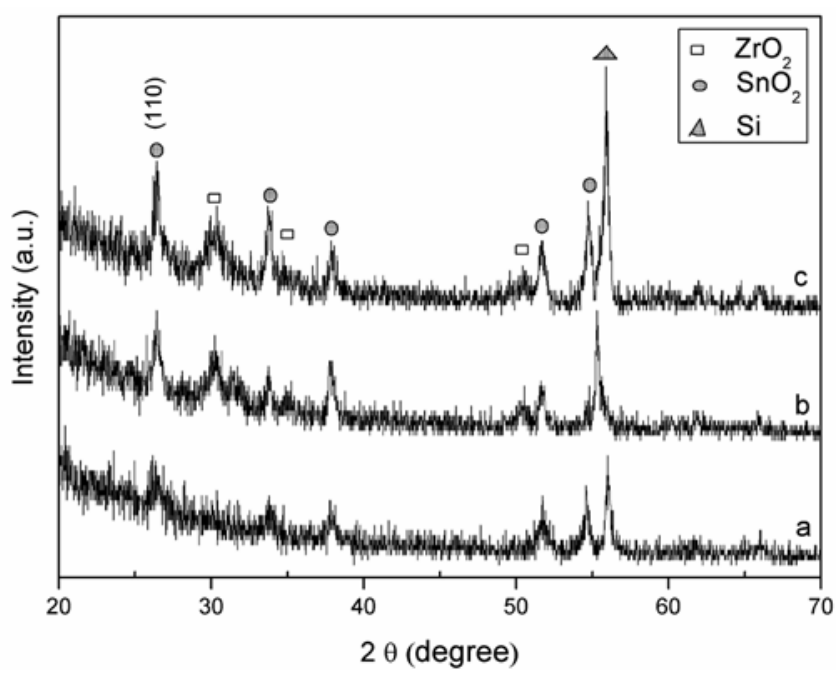

Figure 1. $\mathrm{XRD}$ images of annealed $\mathrm{ZrO}_{2}$ thin films at different temperatures: (a) 300, (b) 500 and (c) $700{ }^{\circ} \mathrm{C}$. bottom electrode (BE) is ATO film and the thickness is about $400 \mathrm{~nm}$. The $\mathrm{ZrO}_{2}$ work layer is about $200 \mathrm{~nm}$ thick and it is amorphous according to the selected area diffraction pattern. Figure 3 shows the interface image of $\mathrm{Cu}$ / $\mathrm{ZrO}_{2}$ /ATO structure in which the $\mathrm{ZrO}_{2}$ thin film was annealed at $500{ }^{\circ} \mathrm{C}$. The $\mathrm{ZrO}_{2}$ work layer is about $100 \mathrm{~nm}$ thick and it is polycrystalline according to the selected

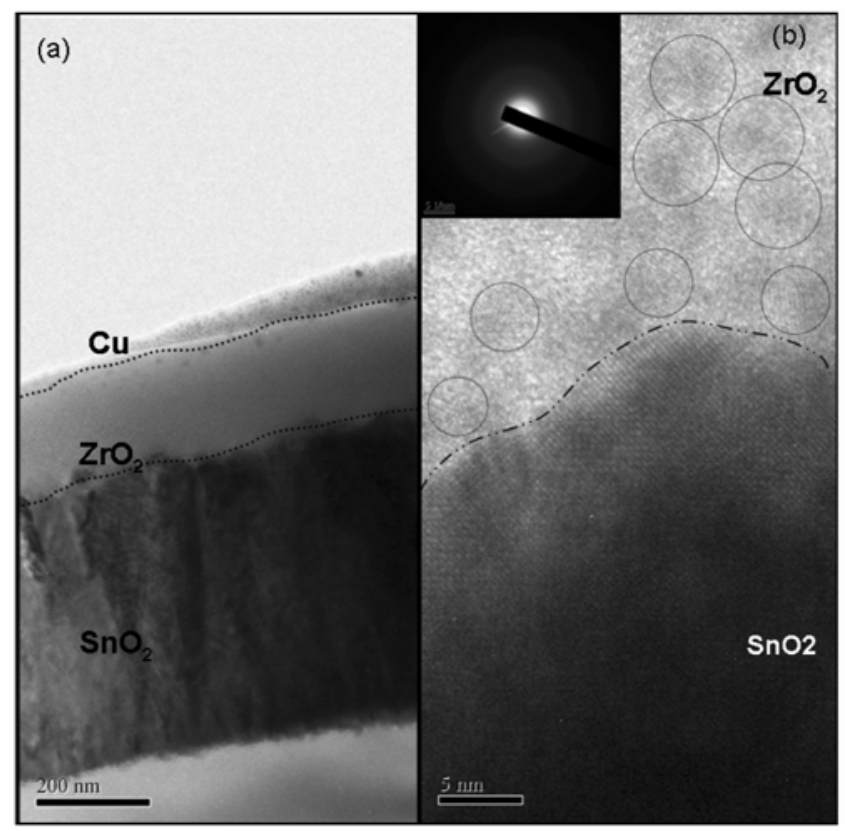

Figure 2. HRTEM images of $\mathrm{Cu} / \mathrm{ZrO}_{2} / \mathrm{ATO}$ structure in which $\mathrm{ZrO}_{2}$ thin film was calcined at $300{ }^{\circ} \mathrm{C}$ and inset image is selected area diffraction (SAD) pattern.

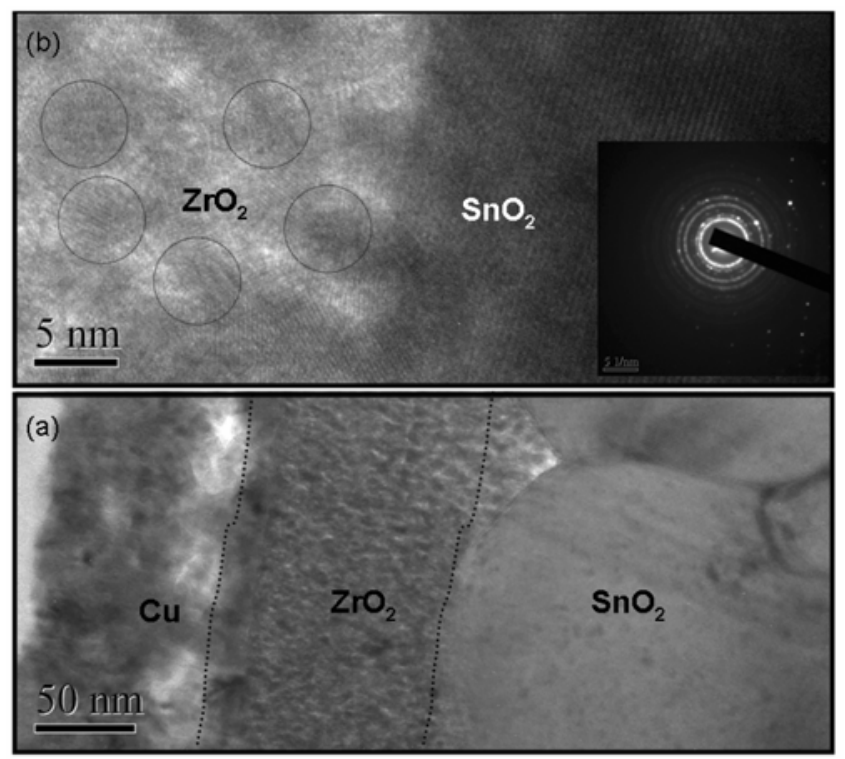

Figure 3. HRTEM images of $\mathrm{Cu} / \mathrm{ZrO}_{2} / \mathrm{ATO}$ structure in which $\mathrm{ZrO}_{2}$ thin film was calcined at $500{ }^{\circ} \mathrm{C}$ and inset image is SAD pattern. 


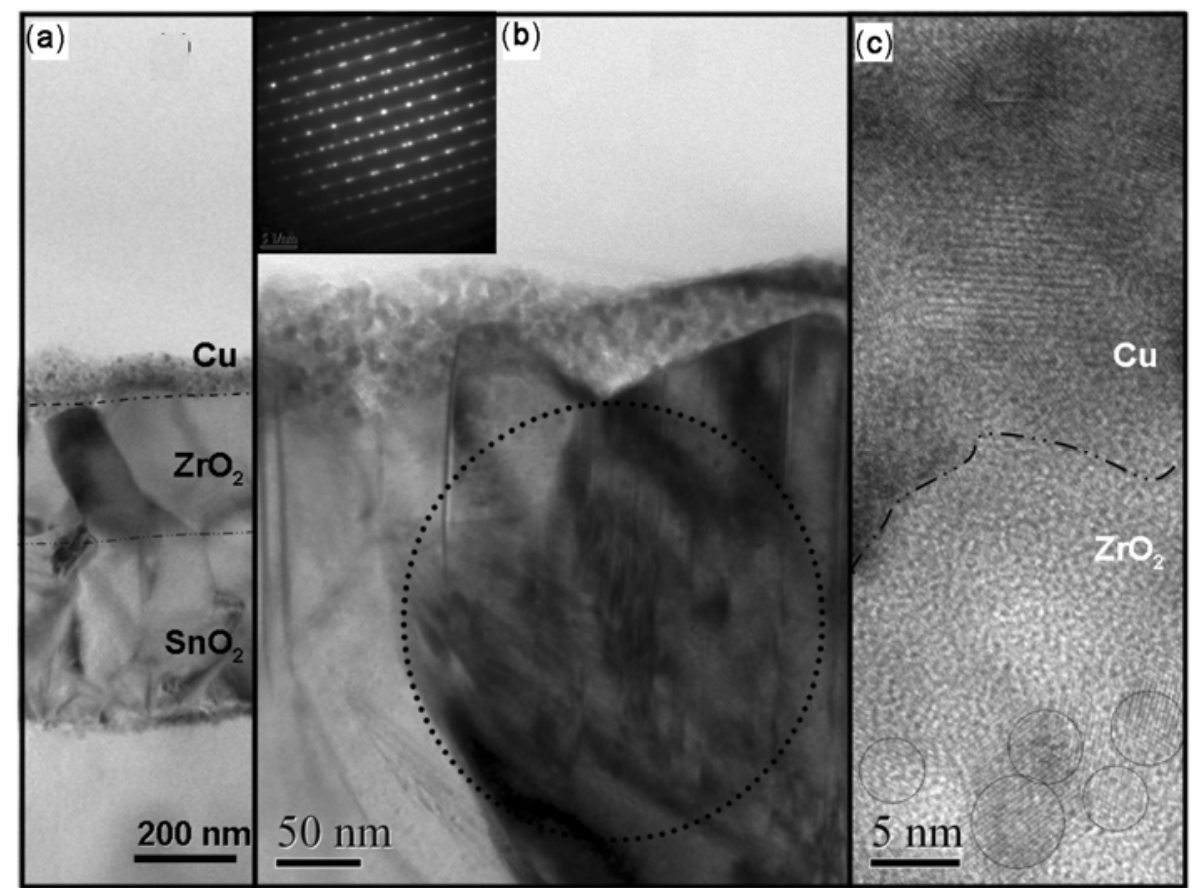

Figure 4. HRTEM images of $\mathrm{Cu} / \mathrm{ZrO}_{2} / \mathrm{ATO}$ structure in which $\mathrm{ZrO}_{2}$ thin film was calcined at $700{ }^{\circ} \mathrm{C}$ and inset image is SAD pattern.
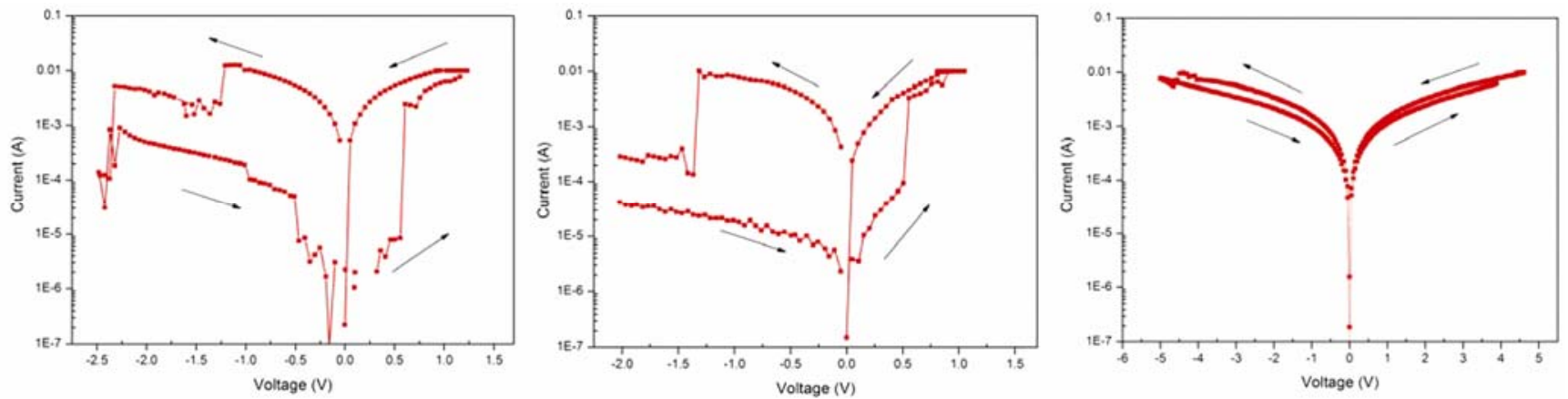

Figure 5. Typical $I-V$ characteristics of $\mathrm{Cu} / \mathrm{ZrO}_{2} / \mathrm{ATO}$ device: (a) 300 , (b) 500 and (c) $700{ }^{\circ} \mathrm{C}$.

area diffraction pattern. Figure 3(b) shows that the grain size of $\mathrm{ZrO}_{2}$ is about $5 \mathrm{~nm}$. Figure 4 shows the interface image of $\mathrm{Cu} / \mathrm{ZrO}_{2} / \mathrm{ATO}$ structure in which the $\mathrm{ZrO}_{2}$ thin film was annealed at $700{ }^{\circ} \mathrm{C}$. The microstructure of $\mathrm{ZrO}_{2}$ grains in figure 4(b) shows twin crystalline due to the selected area diffraction pattern. The interface between $\mathrm{ZrO}_{2}$ and ATO films is obscure. In figure $1, \mathrm{ZrO}_{2}$ and ATO are all showed tetragonal phases. It can be deduced that $\mathrm{ZrO}_{2}$ and ATO grains are grown together. Figures 2-4 show that $\mathrm{Cu}$ ions are penetrated into the $\mathrm{ZrO}_{2}$ layer. It can be proved by the fast Fourier transform (FFT) patterns. According to the filament formation mechanism, resistance reduction in the devices is due to the existing $\mathrm{Cu}$ forming conducting $\mathrm{Cu}$-rich pathways. An opposite bias takes the existing $\mathrm{Cu}$ back to the $\mathrm{Cu}$ electrode to its high-resistance state (Guo et al 2007).
The thickness of $\mathrm{ZrO}_{2}$ thin film formed ranges from 100 to $200 \mathrm{~nm}$ depending on the annealing temperature. It shows that film thickness decreased with an increasing temperature of anneal. It is reported that the thickness of thin film reached a saturation value of $63 \mathrm{~nm}$ at $400{ }^{\circ} \mathrm{C}$ (Korkmaz et al 2012; Soo et al 2012). At the highest temperature of $700{ }^{\circ} \mathrm{C}$, it is deduced that at this temperature the thickness of thin film is no longer affected by densification, but the phase formed to tetragonal $\mathrm{ZrO}_{2}$. $\mathrm{ZrO}_{2}$ and ATO grains grow together. Therefore, the interface between $\mathrm{ZrO}_{2}$ and ATO films is obscure.

For $I-V$ measurements, probes contact top electrode $(\mathrm{Cu})$ and bottom electrode (ATO), respectively. The bottom electrode was grounded. Stable and repeatable $I-V$ curves can be observed in devices in which $\mathrm{ZrO}_{2}$ thin films were annealed at 300,500 and $700{ }^{\circ} \mathrm{C}$. All samples 

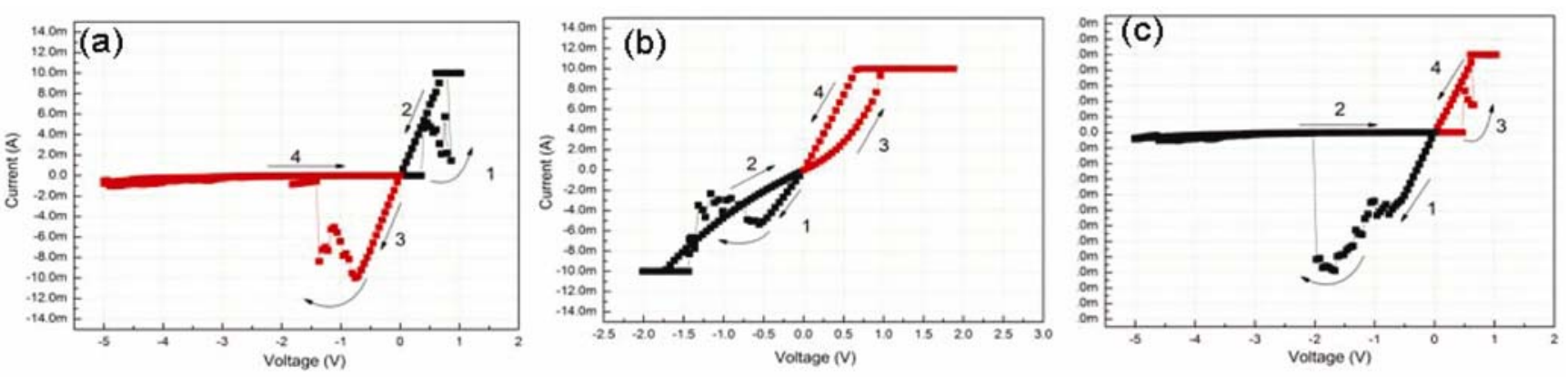

Figure 6. Typical $I-V$ curves of $\mathrm{Cu} / \mathrm{ZrO}_{2}\left(300^{\circ} \mathrm{C}\right) / \mathrm{ATO}$ device with different RESET voltages: RESET voltages at (a) $-5 \mathrm{~V}$, (b) $-2 \mathrm{~V}$ and (c) $-5 \mathrm{~V}$ after recovery.

can show stable bipolar resistive switching at room temperature $(300 \mathrm{~K})$. Figure 5 shows the repeated $I-V$ curves after thirty cycles of $\mathrm{Cu} / \mathrm{ZrO}_{2} / \mathrm{ATO}$ structure in which the $\mathrm{ZrO}_{2}$ thin film which was annealed at 300, 500 and $700{ }^{\circ} \mathrm{C}$. The bipolar resistive switching behaviour was observed and the ratio of $R_{\text {off }} / R_{\text {on }}$ can be reached to $700{ }^{\circ} \mathrm{C}$. For figure 5(a) $I-V$ curve, when the SET voltage reaches $0.55 \mathrm{~V}$, the current increases rapidly which shows switching from the OFF state to the ON state. During the second $I-V$ sweep at the negative side, when the RESET voltage reaches $-1.2 \mathrm{~V}$, the current decreases rapidly which shows switching from the ON state to the OFF state. In figure $5(\mathrm{~b})$, when the SET voltage reaches $0.50 \mathrm{~V}$, the current increases rapidly. It shows switching from the OFF state to the ON state. During the second $I-V$ sweep at the negative side, when the RESET voltage reaches $-1 \cdot 3 \mathrm{~V}$, the current decreases rapidly which shows switching from the ON state to the OFF state. When compared these two curves in figure 5(a and $b$ ), for the SET voltage, it is almost the same while for the reset voltage, the value increases when the annealing temperature increased. For figure 5(c) $I-V$ curve, when the SET voltage reaches $3.8 \mathrm{~V}$, the current increases which shows switching from the OFF state to the ON state. During the second $I-V$ sweep at the negative side, when the RESET voltage reaches $-4.4 \mathrm{~V}$, the current decreases rapidly which shows switching from the ON state to the OFF state. When compared these (a), (b) and (c), (a) and (b) curves are similar. However, for the curve (c), the ratio of $R_{\text {off }} / R_{\text {on }}$ decreases to $1 \cdot 4$. The reasons for the higher voltage could be the existence of grain boundaries and more defects (like twin crystals) in structure because of higher annealing temperatures. This can also be proved by the HRTEM image in figure 4. An increase in the annealing temperatures between 300 and $700{ }^{\circ} \mathrm{C}$ led to the electronic disorder due to oxygen deficiency at a higher oxidation temperature (Ting et al 2000; Korkmaz et al 2012).

Bipolar resistive switching characterization was stable for $\mathrm{ZrO}_{2}$ thin film in the structure unit. Figure 6(a) shows the typical $I-V$ characteristics of the $\mathrm{Cu} / \mathrm{ZrO}_{2} / \mathrm{ATO}$ structure unit. Normally the voltage sweeps starting from $0 \mathrm{~V}$ and goes to the positive side $(5 \mathrm{~V})$ and goes back to $0 \mathrm{~V}$. Resistance switches from high resistance state $\left(R_{\mathrm{H}}\right)$ to low resistance state $\left(R_{\mathrm{L}}\right)$ and it is called SET process. And then the voltage sweeps from $0 \mathrm{~V}$ to the negative side $(-5 \mathrm{~V})$ and goes back to $0 \mathrm{~V}$. Resistance switches from $R_{\mathrm{L}}$ to $R_{\mathrm{H}}$ and it is called RESET process. When the voltage swept at $-0.5 \mathrm{~V}, R_{\mathrm{L}}$ was $70 \Omega$ and $R_{\mathrm{H}}$ was $100 \mathrm{~K} \Omega$. This behaviour can be repeated several times. The current compliance (CC) is applied with $10 \mathrm{~mA}$. The highest ratio of $R_{\mathrm{H}} / R_{\mathrm{L}}$ can be reached to $10^{4}$.

During the RESET operation, we found an interesting thing, i.e. $R_{\mathrm{H}}$ varied when we changed the RESET voltage. $R_{\mathrm{H}}$ decreased when the RESET voltage value decreased. For $I-V$ curve in figure $6(\mathrm{~b})$, voltage sweep started from $0 \mathrm{~V}$ to $-2 \mathrm{~V}$ and then from $-2 \mathrm{~V}$ to $0 \mathrm{~V}$ during the RESET process. When the voltage swept at $-0.5 \mathrm{~V}, R_{\mathrm{L}}$ was $100 \Omega$ and $R_{\mathrm{H}}$ was $250 \Omega$. This behaviour can be repeated several times. The current compliance is applied with $10 \mathrm{~mA}$. The highest ratio of $R_{\mathrm{H}} / R_{\mathrm{L}}$ can be reached to 4 .

When the RESET voltage value goes back to $-5 \mathrm{~V}$, the bipolar resistive curve recovered. In figure 6(c), during the RESET process, voltage sweep started from $0 \mathrm{~V}$ to $-5 \mathrm{~V}$ and then from $-5 \mathrm{~V}$ to $0 \mathrm{~V}$. When the voltage swept at $-0.5 \mathrm{~V}, R_{\mathrm{L}}$ was $65 \Omega$ and $R_{\mathrm{H}}$ was $100 \mathrm{~K} \Omega$. This behaviour can be repeated more than thirty times. The current compliance is applied with $10 \mathrm{~mA}$. The highest ratio of $R_{\mathrm{H}} / R_{\mathrm{L}}$ can be reached to $10^{4}$. With the controllability of the RESET voltage, $R_{\mathrm{L}}$ and $R_{\mathrm{H}}$ values are recovered. Therefore, $R_{\mathrm{L}}$ and $R_{\mathrm{H}}$ value can be controlled by the RESET voltage.

We want to characterize the thermal and electrical properties of the $\mathrm{Cu}$ filament. The conductive filament resistance changes with device's temperature (Russo et al 2009; Peng Gao et al 2010). For low temperature $I-V$ measurement, however, the device $\mathrm{Cu} / \mathrm{ZrO}_{2} / \mathrm{ATO}$, whose $\mathrm{ZrO}_{2}$ was annealed at $300{ }^{\circ} \mathrm{C}$ shows a stable bipolar resistive switching characterization even at low temperature for $I-V$ measurements. $I-V$ sweeps were operated at 200 , 100 and $50 \mathrm{~K}$, respectively. With the Versa Lab system, the voltage compliance was set and it swept the current starting from $0 \rightarrow 70 \mathrm{~mA} \rightarrow 0 \rightarrow-100 \mathrm{~mA} \rightarrow 0$. The 

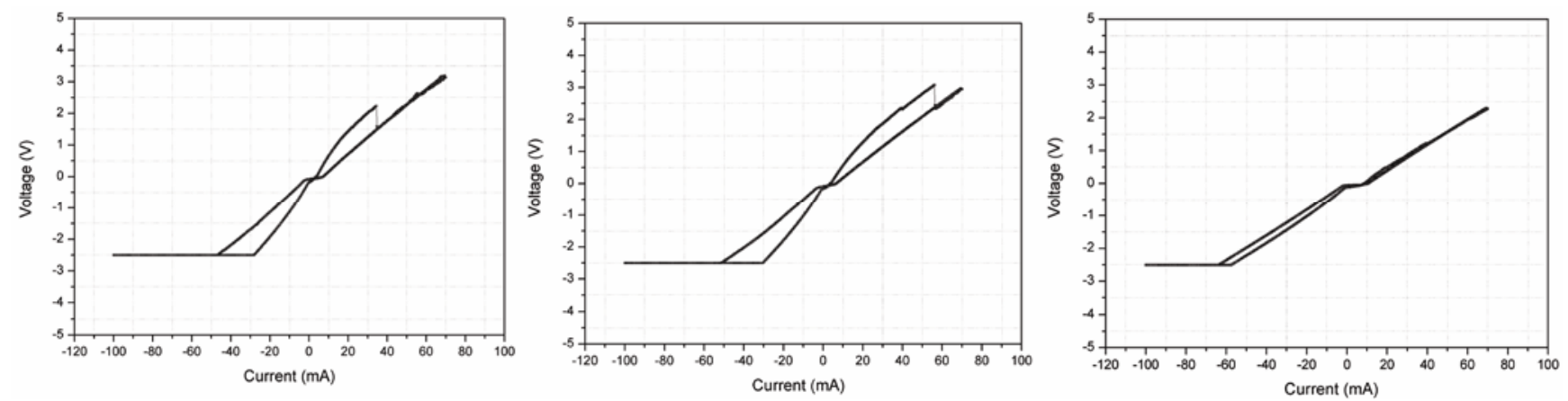

Figure 7. Low temperature $I-V$ characteristics of $\mathrm{Cu} / \mathrm{ZrO}_{2}\left(300{ }^{\circ} \mathrm{C}\right) / \mathrm{ATO}$ device: (a) 200 , (b) 100 and (c) $50 \mathrm{~K}$.

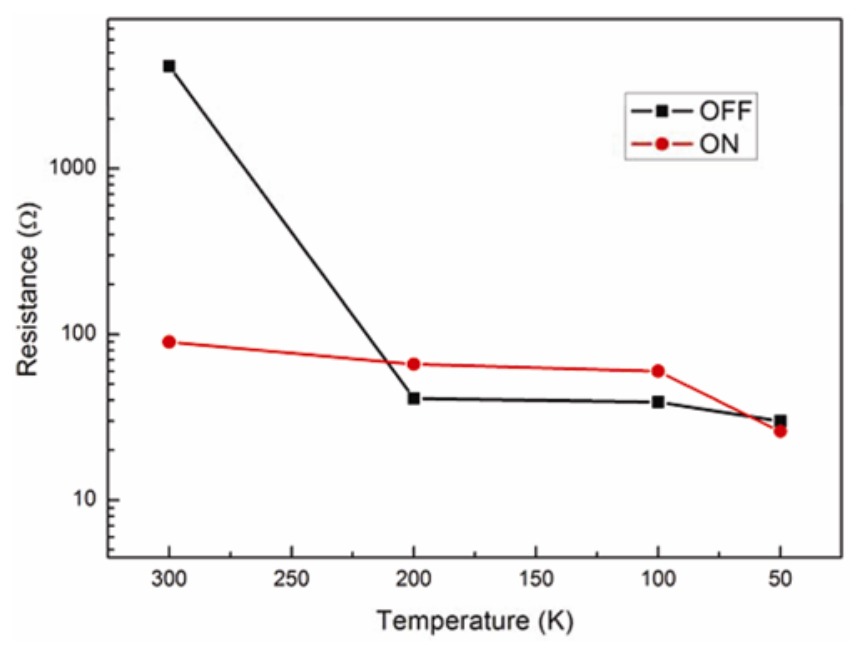

Figure 8. Diagram of temperature impact on $\mathrm{ON}$ and $\mathrm{OFF}$ resistance.

current swept starting from low resistance state. Figure 7 shows the $I-V$ sweep cycles at low temperature (a) 200 , (b) 100 and (c) $50 \mathrm{~K}$. For these curves, it still shows the typical bipolar resistive switching curves even when temperatures decrease to below zero. Therefore, when the temperature decreased, the ratio of $R_{\text {off }} / R_{\text {on }}$ decreased from 1.7 at $200 \mathrm{~K}$ down to 1.1 at $50 \mathrm{~K}$. The reset process of this device is also possible under negative bias, indicating that Joule heating may be responsible for the rupture of the conductive filaments (Schindler et al 2007; Li et al 2010). Figure 8 shows resistances of ON $\left(R_{\mathrm{on}}\right)$ and OFF state $\left(R_{\text {off }}\right)$ in the range from 50 to $300 \mathrm{~K}$. When the temperature decreased, more Joule heating may be needed. On the other hand, when the temperature decreased, the $\mathrm{Cu}$ ions mobility also decreased (El Kamel et al 2006; Russo et al 2007). The resistance of ON state increases owing to the decreasing $\mathrm{Cu}$ which penetrates into $\mathrm{ZrO}_{2}$. When the temperature decreases, $R_{\text {on }}$ decreases obviously which is typical for electronic transportation in a $\mathrm{Cu}$ metal. It is indicated that the $\mathrm{Cu}$ metallic conduction filament has been formed in the $\mathrm{ZrO}_{2}$ films. The metallic resistance as a function of temperature can be written as (Russo et al 2007; Liu et al 2010):

$$
R(T)=R_{0}\left[\left(1+\alpha\left(T-T_{0}\right)\right],\right.
$$

where $R_{0}$ is the resistance at temperature $T_{0}$ and $\alpha$ the resistance temperature coefficient. Figure 8 also shows the temperature dependence of $R_{\text {off }}$. It is different from the $R_{\text {on }}$. For the $R_{\text {off }}$ curve, it changes slightly when the temperature decreases. In the OFF state, the carrier transportation is complicated. Multi-conductive mechanisms may be included.

\section{Conclusions}

We fabricated through sol-gel deposition of $\mathrm{ZrO}_{2}$ thin films post-annealed at 300,500 and $700{ }^{\circ} \mathrm{C}$. Reproducible $I-V$ curves can be obtained with these samples at room temperature $(300 \mathrm{~K})$. The $\mathrm{ZrO}_{2}$ thin film annealed at $300{ }^{\circ} \mathrm{C}$ in $\mathrm{Cu} / \mathrm{ZrO}_{2} / \mathrm{ATO}$ device can also be operated resistive switching sweep cycles at 200, 100 and $50 \mathrm{~K}$. The reasons for the higher leakage current could be the existence of grain boundaries and more defects (like twin crystals) in the structure because of higher annealing temperatures. An increase in the annealing temperatures between 300 and $700{ }^{\circ} \mathrm{C}$ led to the electronic disorder due to oxygen deficiency at a higher oxidation temperature. It was found out the ratio of $R_{\text {off }} / R_{\text {on }}$ reduced at this low temperature. When the $I-V$ measurements temperature decreases, $R_{\text {on }}$ decreases obviously which is typical for electronic transportation in a $\mathrm{Cu}$ metal.

\section{Acknowledgements}

This work is supported by the National Natural Science Foundation of China (no. 51072163). We also thank the Foundation of Excellent Doctoral Dissertation of Xian University of Technology and the Scientific Research Projects of Shaanxi Education Department (no. 11JK0806).

\section{References}

Choi B J et al 2005 J. Appl. Phys. Lett. 98037715

El Kamel F, Gonon P and Jomni F 2006 Thin Solid Films 504 201 
Gao B, Yu S, Xu N, Liu L F and Wang Y Y 2008 Electron devices meeting (San Francisco, USA: IEEE International)

Gopalan C, Kozicki M N and Bhagat S 2007 J. Non-Cryst. Solids $\mathbf{3 5 3} 1844$

Guo X, Schindler C, Stephan M and Waser R 2007 Appl. Phys. Lett. 91133513

Korkmaz S, Pat S, Ekem E, Balbag M Z and Temel S 2012 Vacuum 861930

Li Y, Zhang M and Liu Q 2010 IEEE Electron Device Lett. 31 117

Li Y, Zhao G, Su J, Shen E and Ren Y 2011 Appl. Phys. A104 1069

Liu M, Liu Q, Long S and Guan W 2010 Circuits and Systems (ISCAS), Proc. of IEEE int. symp. pp 1-4
Peng Gao, Zhenzhong Wang, Wangyang Fu and Zhaoliang Liao 2010 Micro. 41301

Russo U, Ielmini D, Cagli C and Lacaita A L 2009 IEEE Trans. Electron Device $\mathbf{5 6} 186$

Russo U, Ielmini D, Cagli C, Lacaita, A L, Spiga S, Wiemer C, Perego M and Fanciulli M 2007 In IEDM tech. dig. IEEE international electron devices meeting (Washington D.C.: IEEE International) pp 775-778

Schindler C, Thermadam S C P, Waser R and Koziki M N 2007 IEEE Trans. Electron Device $\mathbf{5 4} 2762$

Soo M T et al 2012 Appl. Surf. Sci. 2585250

Ting C, Chen S and Liu D 2000 J. Appl. Phys. 88037715

Waser R 2009 Microelectron. Eng. 861925

Zhi X, Zhao G, Zhu T and Li Y 2008 Surf. Interf. Anal. 4067 